\title{
PENERAPAN UNSUR ARSITEKTUR NUSANTARA PADA KARYA DESAIN ARSITEK YU-SING
}

\author{
Sri Winarni \\ Dosen Prodi Arsitektur, Fak. Teknik Sipil dan Perencanaan, ITN Malang \\ e-mail: sriwinarni@lecturer.itn.ac.id \\ Hamka \\ Dosen Prodi Arsitektur, Fak. Teknik Sipil dan Perencanaan, ITN Malang \\ e-mail: hamka07@lecturer.itn.ac.id
}

\begin{abstract}
ABSTRAK
Arsitektur nusantara memiliki pemaknaan yang berbeda-beda oleh berbagai kalangan, namun yang menjadi fokus dari arsitektur nusantara ini adalah bagaimana mempertahankan kearifan lokal yang terkandung didalamnya, baik secara tampilan, konsep lingkungan, sosial dan budaya didalam sebuah rancangan. Permasalahan yang muncul dalam memaknai kembali arsitektur nusantara dalam sebuah rancangan sering kali ditemui pada wujud tampilannya. Banyak desain-desain yang hanya memperhatikan tampilan saja dan melupakan unsur-unsur penting lainnya, sehingga menjadikan desain tersebut hanya meniru dan mengulang tanpa ada pembaharuan. Fokus penelitian ini adalah pada penerapan unsurunsur arsitektur nusantara pada karya desain arsitek Indonesia Yusing yang ide-ide desainnya banyak mengangkat nilai kearifan lokal arsitektur nusantara. Metode yang digunakan dalam penelitian ini, yaitu metode kualitatif, dengan teknik pengumpulan data melalui observasi data karya desain arsitek Yusing, hasil analisis tersebut kemudian diuraikan kualitatif untuk mendapatkan sebuah kesimpulan akhir. Hasil penelitian ini adalah bahwa unsur aspek nusantara secara umum telah diterapkan pada keempat desain karya Yu-sing meskipun tidak diterapkan secara utuh. Desainnya mencoba untuk menginterpretasikan kembali dalam wujud yang baru sesuai dengan perkembangan teknologi saat ini, bukan menghadirkan kembali masa lalu ke masa kini.
\end{abstract}

\section{Kata kunci : arsitektur nusantara, kearifan lokal,karya Yu sing}

\begin{abstract}
Architecture nusantara having meanings by various parties, but really the the focus of architecture nusantara this is how to defend the local wisdom contained therein, it seemed good, the concept of the environment, social and cultural inside a design. The problems that arise in the handling of back architecture nusantara in a design often found in a form of how it looks. Many who designs look out not only the appearance of alone and forget other important elements, that made his design was only fake it and repeat without any renewal. The focus of this study is affected the implementation of elements on works architecture nusantara design yusing indonesian architect whose ideas many raised the value of its design the local wisdom nusantara architecture .Methods used in this research,
\end{abstract}

PAWON: Jurnal Arsitektur, Nomor -- Volume --, Bulan Tahun, ISSN 2597-7636 
namely the qualitative method, collection technique through observation the work of architect yusing design. The analysis was then qualitative outlined to get a final conclusion. The result of this research is that element nusantara aspects in general have been applied to fourth design the work of yu-sing though not applied in their entirety. Design the work of yu sing were trying to the interpretation of the back in a new in accordance with the developments this the technology, not call back the past to the present.

\section{Keywords : Architecture nusantara, the local wisdom, Yu Sing Design}

\section{PENDAHULUAN}

Banyak karya-karya desain arsitek yang terkenal di Indonesia yang fokus desainnya mengarah pada lingkungan binaan arsitektur nusantara, yang mencoba untuk mengangkat kembali dan melestarikan arsitektur nusantara dalam wujud yang kekinian. Kajian penelitian ini merupakan kajian karya desain arsitek terkenal di Indonesia salah satunya karya YuSing. Dalam karyanya, Yu Sing memiliki konsep perancangan yang sustainable dengan memanfaatkan potensi lokal, ramah terhadap lingkungan dan menggunakan material daur ulang. Dari hasil kajian tersebut dapat disimpulkan mengenai penerapan unsur-unsur apa saja yang menjadi kelebihan dan kekurangan dalam desain karya arsitek Yu-Sing. Arsitektur nusantara bukan hanya sekadar tampilan saja, tetapi memiliki kearifan lokal baik secara lingkungan, sosial, dan budaya masyarakat setempat, sehingga perlu diketahui juga apakah unsur-unsur tersebut sudah diterapkan dalam desain karya Yu-Sing. Hasil penelitian ini nantinya diharapkan dapat dijadikan rujukan atau pedoman dalam melakukan kajian desain arsitektur nusantara dalam desain rancangan.

\section{TINJAUAN PUSTAKA}

\subsection{Konsep Arsitektur Nusantara}

(a). Konsep hirarki pada sumbu vertikal dan horizontal

Masyarakat nusantara terdahulu telah membagi spasial dunia dalam tiga lapis, dunia atas disimbolkan sebagai (surga, kahyangan), dunia bawah yang bermakna dunia maut dan dunia tengah yang merupakan dunia bagi manusia untuk bertempat tinggal. Pola yang terdapat pada dunia mikro hunian merupakan cerminan dari dunia makro alam raya. Oleh sebab itu, wujud bentuk suatu hunian selalu memiliki beberapa analogi bentuk dasar, contohnya bentuk atap yang menyerupai bentuk gunung, gunung dalam hal ini selalu diidentifikasi sebagai tanah tinggi, suatu tempat yang dianggap paling dekat dengan Tuhan di dunia atas (Mangunwijaya, 1988). Rumah dianggap sebagai bentuk mikro kosmos, sebagai penjelmaan dari bentuk makro kosmos (alam raya), yaitu dunia atas, tengah dan bawah (Moerdjoko dalam Mashuri, 2012). 
(b). Konsep Skala dan Proporsi Manusia

Rumah tradisional Jawa dibangun dengan menggunakan konsep keharmonisan antara manusia dengan Sang Pencipta, manusia dengan alam semesta (moncopat, kolomudheng, ponco sudho, papat keblat kalima pancer) dan hubungan antara manusia dengan manusa (Roesmanto, 1999). Struktur spasial tradisional rumah tinggal perlu dijelaskan terlebih dahulu mengenai aturan-aturan yang berlaku, di Jawa sama halnya di tempat lain, manusia adalah ukuran benda (protagoras), sedangkan benda-benda dan alat-alat memakai ukuran yang sesuai dengan badan manusia (Atmadi dalam Frick, 2001).

(c). Konsep Orientasi

Arsitektur tradisional tidak lahir begitu saja, namun syarat dengan filsafat, nilai tradisi, dan kepercayaan, seperti arah dan letak permukiman dan rumah terkait dengan faktor keberuntungan dan keselamatan penghuni rumah, penentuan arah ini menjadi sangat penting bahkan disakralkan dan hal yang menjadi patokan biasanya adalah gunung, matahari, laut, dan kiblat (Idawarni, 2011).

(d). Konsep Struktur

Struktur dan konstruksi pada arsitektur tradisional merupakan elemen pembentuk spasial yang mengandung nilai dan makna. Contohnya pada rumah joglo, konstruksi bangunan yang khas dengan fungsi setiap bagian yang berbeda satu sama lain yang mengandung unsur filosofis terkait nilai dan makna, seperti struktur tiang penyangga utama (saka guru) yang berjumlah empat membentuk formasi persegi (Djono et al, 2012). Elemen struktur berfungsi mempertegas dan memperkuat keberadaan spasial dimana aktifitas berlangsung dan terbentuk sebagai spasial diantara dua elemen massa yang berbeda dan berperan sebagai spasi atau spasial antara/penghubung (Zuhri, 2005).

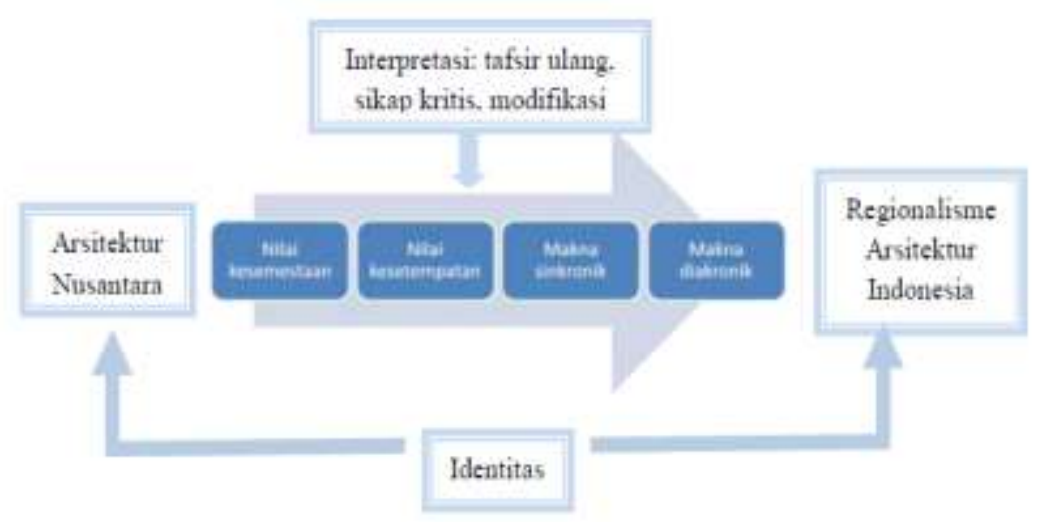

Gambar. 2.1. Arsitektur Nusantara, dasar Pembentuk Regionalisme Arsitektur di Indonesia. (Sumber: Hidayatun, 2014)

PAWON: Jurnal Arsitektur, Nomor -- Volume --, Bulan Tahun, ISSN 2597-7636 


\section{METODE PENELITIAN}

Tahapan pengumpulan data dilakukan dengan pemilihan data dan sumber data yang disesuaikan dengan variabel yang diteliti serta cara mengumpulkannya. Ada dua jenis data, yaitu data primer dan data sekunder. Data primer merupakan data yang berhubungan langsung dengan fokus penelitian. Data-data primer mengenai gambaran karya desain arsitek didapatkan dari berbagai media berupa majalah, blog-blog internet, jurnal, dan koleksi pribadi. Data ini yang akan diolah dan dianalisis berdasarkan variable penelitian untuk diambil satu kesimpulan akhir.

Data sekunder diperoleh dari dokumen dan informasi umum berupa buku, publikasi dan hasil penelitian tentang desain arsitektur nusantara dan karya desain arsitek Indonesia. Pengumpulan data sekunder dilakukan dengan mengumpulkan sumber-sumber informasi yang berkaitan dengan objek yang diteliti.

Variabel penelitian meliputi variabel persepsi visual yaitu visual dari bentuk (wujud, dimensi, warna, tekstur, posisi, orientasi, dan inersia visual) berupa dan juga unsur-unsur yang terdapat pada arsitektur nusantara terkait dengan identitas kelokalan, ornamentasi, material. Variabel-variabel yang dijadikan sebagai bahan kajian akan terfokus pada persepsi indra visual, yaitu elemen-elemen yang dapat dirasakan dan dilihat oleh mata dan melihat unsur-unsur arsitektur nusantara apa saja yang diterapkan dimasing-masing desain (pola tata letak, konstruksi, hirarki, orientasi, material dan ornamentasi).

\section{HASIL DAN PEMBAHASAN}

\section{a. Objek penelitian}

Tabel 1. Objek penelitian

\begin{tabular}{llcc}
\hline No. & \multicolumn{1}{c}{ Objek } & Lokasi & Terapan srsitektur tradisonal \\
\hline 1 & $\begin{array}{l}\text { Rumah Nias } \\
\text { Cimanggis }\end{array}$ & Jakarta & Rumah tradisonal Nias Selatan \\
\hline 2 & $\begin{array}{l}\text { Rumah } \\
\text { Betang } \\
\text { Kalimantan }\end{array}$ & Kalimantan & Rumah Betang/ Panjang \\
\hline 3 & $\begin{array}{l}\text { Menara } \\
\text { Pinisi } \\
\text { Universitas } \\
\text { Negeri } \\
\text { Makassar }\end{array}$ & Makassar & Perahu Pinisi dan Rumah Makassar \\
& & & \\
\hline 4 & Studio & Padalarang-Bandung & Rumah Jawa \\
& Akanoma & & \\
\hline
\end{tabular}

PAWON: Jurnal Arsitektur, Nomor -- Volume --, Bulan Tahun, ISSN 2597-7636 


\section{b. Identifikasi dan Analisis Aspek Desain Nusantara}

\section{Rumah Nias Cimanggis}

Rumah Nias Cimanggis merupakan reinterpretasi dari Rumah adat Nias. Bentuk bangunan semi panggung dengan model atap di sederhanakan. Sedangkan untuk pola rumah juga berderet seperti di kampung Nias Selatan dengan pola yang tidak terpisah-pisah. Bangunan rumah Cimanggis ini memiliki ruang pesta yang menyatukan taman gasebo, kolam, teras dan ruang keluarga, letaknya berada dibawah panggung. Untuk fasad bangunannya terdapat jalusi-jalusi kayu.
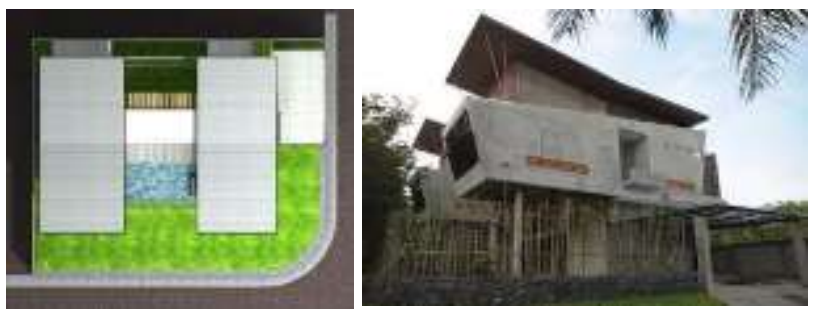

Gambar. 1. Rumah nias cimanggis

Sumber : rumah-yusing.blogspot.com

Tabel. 2. Hasil identifikasi dan analisis aspek desain

\begin{tabular}{|c|c|c|c|c|}
\hline \multirow[t]{2}{*}{ No. } & \multirow[t]{2}{*}{$\begin{array}{c}\text { Aspek } \\
\text { Nusantara }\end{array}$} & \multicolumn{2}{|c|}{$\begin{array}{c}\text { Penerapan } \\
\text { Aspek Desain }\end{array}$} & \multirow[t]{2}{*}{ Penjelasan } \\
\hline & & Ada & $\begin{array}{c}\text { Tidak } \\
\text { ada }\end{array}$ & \\
\hline 1 & Pola tata letak & & $\sqrt{ }$ & $\begin{array}{l}\text { Penerapan pola tata letak pada rumah } \\
\text { cimanggis tidak sepenuhnya sesuai } \\
\text { dengan rumah tradisional aslinya, terjadi } \\
\text { perubahan pola. }\end{array}$ \\
\hline 2 & Konstruksi & $\sqrt{ }$ & & $\begin{array}{l}\text { Hanya pada tampilan kolom bulat yang } \\
\text { disesuaikan dengan tampilan pada rumah } \\
\text { tradisional aslinya }\end{array}$ \\
\hline 3 & Bentuk & $\sqrt{ }$ & & Diterapkan melalui metode transformasi \\
\hline 4 & Orientasi & $\sqrt{ }$ & & $\begin{array}{l}\text { Sesuai dengan konsep rumah tradisional } \\
\text { nias yang asli }\end{array}$ \\
\hline 5 & Material & $\sqrt{ }$ & & $\begin{array}{l}\text { Sudah mengalami perubahan sesuai } \\
\text { dengan kebutuhan, namun terdapat } \\
\text { beberapa material seperti bamboo dan } \\
\text { kayu yang masih dipertahankan pada } \\
\text { beberapa spot ornamentasi. }\end{array}$ \\
\hline 6 & Ornamentasi & $\sqrt{ }$ & & $\begin{array}{l}\text { Penerapan ornamentasi pada kisi-kisi } \\
\text { jendela yang tampilannya disesuaikan } \\
\text { dengan tampilan asli dari rumah tradisional } \\
\text { nias. }\end{array}$ \\
\hline
\end{tabular}

PAWON: Jurnal Arsitektur, Nomor -- Volume --, Bulan Tahun, ISSN 2597-7636 


\section{Rumah Betang}

Rumah Betang merupakan rumah yang terinspirasi oleh Rumah Panjang Kalimantan. Rumah Betang ini memiliki 2 fungsi, rumah tinggal di bagian sisi sebelah kanan dan kantor di bagian sisi sebelah kiri. Rumah Betang ini menggunakan material bahan daur ulang. Material bahan yang digunakan sebagian kayu bekas yang digunakan kembali dan juga sebagian kayu baru. Struktur bangunan rumah Betang menggunakan kayu ulin. Untuk bentuk fasadnya terdapat motif khas Kalimantan yaitu motif dayak akar betaut.
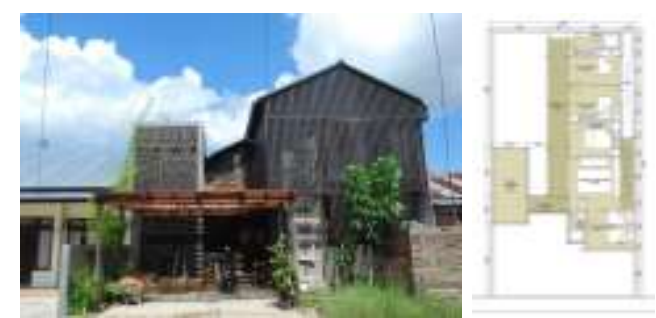

Gambar 2. Tampak dan denah rumah Betang Sumber : rumah-yusing.blogspot.com

Tabel. 3. Hasil identifikasi dan analisis aspek desain

\begin{tabular}{|c|c|c|c|c|}
\hline \multirow[t]{2}{*}{ No. } & \multirow[t]{2}{*}{$\begin{array}{c}\text { Aspek } \\
\text { Nusantara }\end{array}$} & \multicolumn{2}{|c|}{$\begin{array}{c}\text { Penerapan } \\
\text { Aspek Desain }\end{array}$} & \multirow[t]{2}{*}{ Penjelasan } \\
\hline & & Ada & $\begin{array}{c}\text { Tidak } \\
\text { ada }\end{array}$ & \\
\hline 1 & Pola tata letak & $\sqrt{ }$ & & $\begin{array}{l}\text { Secara konsep tatanan ruang atau perletakan } \\
\text { ruang-ruang, desain rumah betang ini berusaha } \\
\text { untuk mempertahankan pola tatanan ruang atau } \\
\text { letak ruang berupa bilik-bilik yang berderet } \\
\text { dengan ruang berkumpul bersama yang berada } \\
\text { ditengah dan diapit oleh kamar-kamar tidur dan } \\
\text { pada bagian ujungnya masing-masing diapit } \\
\text { kamar mandi. }\end{array}$ \\
\hline 2 & Konstruksi & $\sqrt{ }$ & & $\begin{array}{l}\text { Penerapan hanya pada modul struktur kolom } \\
\text { yang dibuat teratur/ berderet sesuai pola ruang } \\
\text { atau bilik-bilik kamar yang ada }\end{array}$ \\
\hline 3 & Bentuk & $\sqrt{ }$ & & $\begin{array}{l}\text { Diterapkan melalui metode transformasi, } \\
\text { terdapat beberapa bagian yang dihilangkan dan } \\
\text { tampilan yang diperbaharui }\end{array}$ \\
\hline 4 & Orientasi & & $\sqrt{ }$ & Menyesuaikan dengan kondisi eksisting tapak \\
\hline 5 & Material & $\sqrt{ }$ & & $\begin{array}{l}\text { Sudah mengalami perubahan sesuai dengan } \\
\text { kebutuhan, namun penggunaan material kayu } \\
\text { masih dominan pada fasade rumah yang } \\
\text { ditampilkan }\end{array}$ \\
\hline
\end{tabular}

PAWON: Jurnal Arsitektur, Nomor -- Volume --, Bulan Tahun, ISSN 2597-7636 

dan diterapkan pada elemen fasade dan interior rumah

\section{Menara Phinisi}

Menara Phinisi merupakan karya Yu Sing yang menjadi pemenang pertama sayembara Gedung Pusat Pelayanan Administrasi Universitas Negeri Makasar (GPPA UNM). Bangunan GPPA UNM merupakan bangunan tinggi bertingkat 17 lantai. Bangunan GPPA UNM ini memiliki konsep yang mengangkat kekayaan budaya Makasar, nilai-nilai filosofi, budaya dan arsitektur tradisional. Konsep-konsep tersebut menjadi sumber inspirasi desain GPPA UNM dalam menunjukkan identitas dan lokalitas arsitektur yang berkelas dunia.

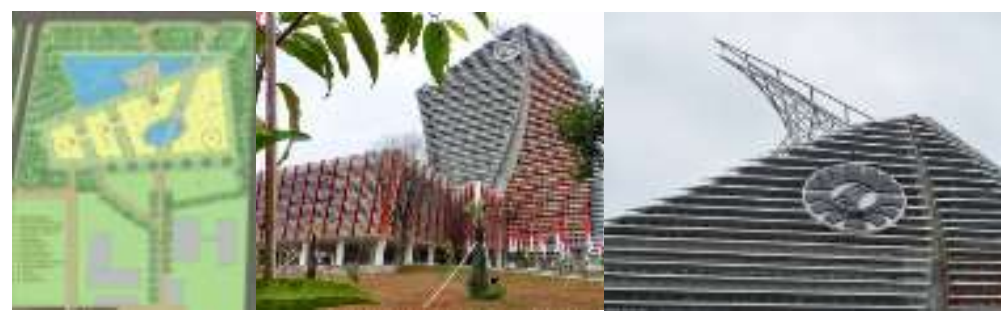

Gambar. 3. Gedung Pusat Pelayanan Akademik UNM Sumber : https://www.kompasiana.com

Menara Phinisi merupakan gedung tinggi pertama di Indonesia dan juga sebagai ikon kota Makasar. Kearifan lokal dalam karya ini dimaknai pada Logo UNM, Rumah Tradisional Makassar, falsafah hidup masyarakat Sulawesi Selatan dan maha karya Perahu Pinisi sebagai simbol kejayaan, kebanggaan, dan keagungan orang Makasar, sehingga desain Karya GPPA UNM ini memiliki serangkaian makna, fungsi yang perwujudannya diaplikasikan kedalam desain arsitektur dengan kecanggihan ilmu pengetahuan dan teknologi. Dalam hal ini dapat kita lihat dari sistem fasade Hiperbolic Paraboloid dan ekspresi futuristic.

Tabel. 4. Hasil identifikasi dan analisis aspek desain

\begin{tabular}{cccc}
\hline No. & $\begin{array}{c}\text { Aspek } \\
\text { Nusantara }\end{array}$ & $\begin{array}{c}\text { Penerapan } \\
\text { Aspek Desain }\end{array}$ & Penjelasan \\
\hline & Ada $\begin{array}{c}\text { Tidak } \\
\text { ada }\end{array}$ & \\
\hline 1 & Pola tata letak & $\sqrt{ }$ & $\begin{array}{c}\text { Penerapan pola tata letak pada GPPA UNM } \\
\text { sesuai dengan konsep penerapan terhadap }\end{array}$ \\
\hline
\end{tabular}

PAWON: Jurnal Arsitektur, Nomor -- Volume --, Bulan Tahun, ISSN 2597-7636 


\begin{tabular}{|c|c|c|c|}
\hline & & & $\begin{array}{l}\text { arsitektur tradisional Makasar, falsafah } \\
\text { hidup masyarakat Sulawesi Selatan serta } \\
\text { simbol perahu phinisi }\end{array}$ \\
\hline 2 & Konstruksi & $\sqrt{ }$ & $\begin{array}{l}\text { Penerapannya hanya pada tampilan kolom } \\
\text { pada kolong/panggung yang disesuaikan } \\
\text { dengan tampilan pada rumah tradisional } \\
\text { Makasar. }\end{array}$ \\
\hline 3 & Bentuk & $\sqrt{ }$ & $\begin{array}{l}\text { perpaduan arsitektur lokal nusantara yang } \\
\text { penuh filosofi dengan arsitektur modern } \\
\text { masa kini yang penuh dengan kecanggihan } \\
\text { teknologi dan ilmu pengetahuan }\end{array}$ \\
\hline 4 & Orientasi & $\sqrt{ }$ & $\begin{array}{l}\text { Sesuai dengan konsep rumah tradisional } \\
\text { Makasar }\end{array}$ \\
\hline 5 & Material & $\sqrt{ }$ & $\begin{array}{l}\text { Perubahan material karena jenis dan fungsi } \\
\text { bangunan }\end{array}$ \\
\hline 6 & Ornamentasi & $\sqrt{ }$ & $\begin{array}{l}\text { Penerapan ornamentasi pada sirip-sirip } \\
\text { secondary skin, kaca reflektor matahari } \\
\text { serta Kanopi-kanopi photovoltaic } \\
\text { disesuaikan dengan tampilan asli dari } \\
\text { rumah tradisional Makasar. }\end{array}$ \\
\hline
\end{tabular}

\section{Akanoma studio}

Studio Akanoma ini terletak di perkampungan jalan Tipar Timur Rt 04 Rw 01, Desa Laksana Mekar, Padalarang, Bandung Barat. Studio ini menggunakan konstruksi atap joglo pendhopo omah Jawa sebagai konstruksi utamanya. Pendhopo yang dibangun berada diatas panggung, terdapat tiang berbentuk dahan pohon besar yang menyangga studio (pendhopo).

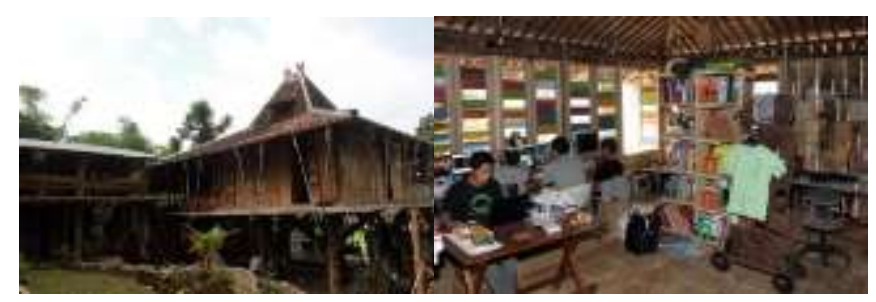

Gambar. 4.7 Akanoma, Studio Ramah Lingkungan

Sumber : http://panduanwisata.id

Akanoma studio terdiri dari dua lantai, lantai satu disebut ruang serba guna atau kolong karena selain aktivitas sehari-hari bahkan juga digunakan untuk warga sekitar yang berkunjung, lantai ke dua digunakan untuk studio, ruang rapat dan dapur. Material bahan yang digunakan adalah material kayu dan bambu, mulai dari atap, dinding, jendela, ventilasi, lantai, tangga hingga ke perabot yang ada didalamnya. 
Tabel. 5. Hasil identifikasi dan analisis aspek desain

\begin{tabular}{|c|c|c|c|c|}
\hline No. & $\begin{array}{l}\text { Aspek } \\
\text { Nusantara }\end{array}$ & $\begin{array}{l}\text { Pen } \\
\text { Aspe }\end{array}$ & $\begin{array}{l}\text { apan } \\
\text { esain }\end{array}$ & Penjelasan \\
\hline & & Ada & $\begin{array}{l}\text { Tidak } \\
\text { ada }\end{array}$ & \\
\hline 1 & Pola tata letak & & $\sqrt{ }$ & $\begin{array}{l}\text { Penerapan pola tata letak pada studio } \\
\text { akanoma tidak sepenuhnya sesuai } \\
\text { dengan rumah tradisional aslinya, terjadi } \\
\text { perubahan pola, letaknya berada atas } \\
\text { panggung. }\end{array}$ \\
\hline 2 & Konstruksi & $\sqrt{ }$ & & $\begin{array}{l}\text { Hanya pada tampilan kolom dan atap } \\
\text { yang disesuaikan dengan tampilan pada } \\
\text { rumah tradisional aslinya }\end{array}$ \\
\hline 3 & Bentuk & $\sqrt{ }$ & & Diterapkan melalui metode transformasi \\
\hline 4 & Orientasi & & $\sqrt{ }$ & tidak sesuai dengan konsep rumah jawa \\
\hline 5 & Material & $\sqrt{ }$ & & $\begin{array}{l}\text { Tetap mempertahankan kayu dan juga } \\
\text { penambahan bambu dan beton }\end{array}$ \\
\hline 6 & Ornamentasi & $\sqrt{ }$ & & $\begin{array}{l}\text { Penerapan ornamentasi pada bangunan } \\
\text { lantai } 2 \text { lebih banyak tampilannya yang } \\
\text { disesuaikan dengan tampilan asli dari } \\
\text { rumah tradisional Jawa }\end{array}$ \\
\hline
\end{tabular}

\section{KESIMPULAN}

Berdasarkan keenam variable elemen nusantara yang diterapkan pada karya desain arsitek Yu-sing ditemukan bahwa unsur aspek nusantara secara umum telah diterapkan pada keempat desain karya Yu-sing meskipun tidak diterapkan secara utuh, namun melalui proses transformasi dalam bentuk pengurangan, penambahan atau dihilangkan. Hal tersebut disesuaikan dengan kebutuhan dan perkembangan teknologi saat ini. Desainnya mencoba untuk diinterpretasikan kembali dalam wujud yang baru sesuai dengan kondisi saat ini, bukan menghadirkan kembali masa lalu ke masa kini.

\section{DAFTAR PUSTAKA}

Adiyanto (2012). Ruang Bersama di Kolong Studio Akanoma (Ke-kini-an Arsitektur Jawa). Seminar Nasional Semesta Arsitektur Nusantara (SAN) Universitas Brawijaya Malang

Bramantyo, 2012. Identifikasi Arsitektur Rumah Tradisional Nias Selatan Dan Perubahannya. Jurnal Permukiman Vol. 7 No. 3 November 2012 : 151 161.

Dahniar,et al (2013). Tipologi Bentuk Jendela pada Rumah Tradisional Bugis di Taman Miniatur Sulawesi Selatan, Benteng Somba Opu Makassar.Temu IImiah IPLBI 2013. 
Frick, Heinz. 2001. Pola Struktural dan Teknik Bangunan di Indonesia. Kanisius:Yogyakarta

Hidayatun, et al (2014). Arsitektur Nusantara Sebagai Dasar Pembentuk Regionalisme Arsitektur Indonesia. Seminar Rumah Tradisional 2014 Transformasi Nilai-nilai Tradisional dalam Arsitektur Masa Kini.

Hasan, et al ( 2002). Perubahan Bentuk dan Fungsi Arsitektur Tradisional Bugis di Kawasan Pesisir Kamal Muara, Jakarta Utara. International Symposium 'Building Research and the Sustainability of the Built Environment in the Tropics'.

Idawarni, 2011. Penentuan Arah dan Letak Permukiman dan Rumah Tinggal Kaitannya dengan Kosmologi, Studi Kasus: Kampung Kanarea, Kecamatan Bajeng Gowa Sulawesi Selatan. Local Wisdom-Jurnal IImiah Online, ISSN: 20863764. Volume: III, Nomor: 1, Hal: 09-18.

Johansen, 2009. Arsitektur Rumah Betang (Radakng) Kampung Sahapm. Patanjala Vol. 6 No. 3, September 462 2014: 461-474l

Mashuri, 2012. Perwujudan Kosmologi Pada Bangunan Rumah Tradisional Toraja. LANTING Journal of Architecture, Volume 1, Nomor 1, Februari 2012, Halaman 1-10 ISSN 2089-8916

Nandang, 2010. PERSEPSI TREN ARSITEKTUR BANGUNAN MINIMALIS PADA DESAIN ARSITEKTURAL PERUMAHAN. JURNAL TEKNIK UNISFAT, Vol. 6, No. 1, September 2010 Hal $10-20$

http://rumah-yusing.blogspot.com/2011/06/reintepretasi-rumah-nias.html http://rumah-yusing.blogspot.com/2011/06/reinterpretasi-rumah-betang.html http://rumah-yusing.blogspot.com/2009/01/menara-pinisi.html https://www.kompasiana.com/354313354/5529828af17e61037cd623b9/unik nya-desain-menara-phinisi-unm http://panduanwisata.id/2014/09/19/akanoma-studio-ramah-lingkungan/ https://rotyyu.wordpress.com/2011/04/06/petualanganku-di-kota-makassarujung-pandang-2/

https://archnet.org/sites/6993/media_contents/79587 